\title{
The effect of whey acidic protein fractions on bone loss in the ovariectomised rat
}

\author{
Marlena C. Kruger ${ }^{1}$, Gabrielle G. Plimmer ${ }^{1}$, Linda M. Schollum², Neill Haggarty ${ }^{2}$, Satyendra Ram ${ }^{2}$ and \\ Kate Palmano ${ }^{2}$ \\ ${ }^{1}$ Institute of Food, Nutrition and Human Health, Massey University, Private Bag 11222, Palmerston North, New Zealand \\ ${ }^{2}$ Fonterra Research Centre, Private Bag 11029, Palmerston North, New Zealand \\ (Received 31 May 2004 - Revised 21 January 2005 - Accepted 3 February 2005)
}

\begin{abstract}
Bovine milk has been shown to contain bioactive components with bone-protective properties. Earlier studies on bovine milk whey protein showed that it suppressed bone resorption in the female ovariectomised rat. A new osteotropic component was subsequently identified in the whey basic protein fraction, but bone bioactivity may also be associated with other whey fractions. In the present study, we investigated whether acidic protein fractions isolated from bovine milk whey could prevent bone loss in mature ovariectomised female rats. Six-month-old female rats were ovariectomised (OVX) or left intact (sham). The OVX rats were randomised into four groups. One group remained the control (OVX), whereas three groups were fed various whey acidic protein fractions from milk whey as $3 \mathrm{~g} / \mathrm{kg}$ diet for 4 months. Outcomes were bone mineral density, bone biomechanics and markers of bone turnover. Bone mineral density of the femurs indicated that one of the whey AF over time caused a recovery of bone lost from OVX. Plasma C-telopeptide of type I collagen decreased significantly in all groups except OVX control over time, indicating an anti-resorptive effect of whey acidic protein. Biomechanical data showed that the AF may affect bone architecture as elasticity was increased by one of the whey AF. The femurs of AF-supplemented rats all showed an increase in organic matter. This is the first report of an acidic whey protein fraction isolated from milk whey that may support the recovery of bone loss in vivo.
\end{abstract}

Ovariectomised rat: Whey acidic protein: Bone density: Bone breaking strength: Biochemical markers of bone turnover

Osteoporosis is one of the most critical disorders occurring in women with advancing age. During menopause, there is a change in bone turnover, with an imbalance between bone formation and bone resorption resulting in net bone loss. Bone loss as a result of oestrogen deficiency is primarily caused by an increase in the activity of the osteoclast (Omi \& Ezawa, 1995).

Nutritional components with potential anti-resorptive activity generally include only $\mathrm{Ca}$ and to some extent cholecalciferol. The Ca found in milk has an anti-resorptive effect and can help to prevent bone loss (Heaney, 2000). Milk (and colostrum) also contains a number of other components that may be boneactive. These include whey protein components, lipids and a large number of caseins, all of which are phosphoproteins (Delisle et al. 1995). In particular, milk contains a highly phosphorylated protein, osteopontin, which has been implicated in bone mineralisation (Bayless et al. 1997). Milk also contains bioactive peptides with an anti-resorptive activity (Neeser et al. 2000). Similarly, whey may contain certain growth factors affecting bone (Takada et al. 1993).

Takada et al. $(1997 a, b)$ showed that milk whey protein suppressed bone resorption in the female ovariectomised rat. Toba et al. $(1999,2000)$ subsequently described a new osteotropic component in the whey basic protein fraction of milk (later called milk basic protein), and animal studies showed that it suppressed bone resorption. Results also showed that the milk basic protein had no effect on $\mathrm{Ca}$ absorption, as calculated using $\mathrm{Ca}$ balance data, but that it enhanced bone strength in the ovariectomised rat model (Takada et al. 1997a,b).

A recent study in young growing male rats showed that feeding whey protein increased alkaline phosphatase activity and insulinlike growth factor-I (IGF-I) mRNA levels in ectopic bone (Kelly et al. 2003). As alkaline phosphatase is a marker for bone formation, whereas IGF-I is a known potent anabolic agent (Price et al. 1994), this further indicated a possible effect of whey protein on bone formation.

In contrast to the basic whey protein fractions, little is known of the possible benefits of the acidic protein peptide fractions from milk. The acidic (low isoelectric point) protein component of whey is known to contain phosphorylated proteins and peptides (Sorensen \& Petersen, 1993; Reid et al. 2004), some of which might play a role in $\mathrm{Ca}$ absorption. Additionally, the whey acidic protein (WAP) complement contains osteopontin (and likely fragments thereof; K Palmano, unpublished data), which is essential to bone mineralisation (Bayless et al. 1997; Denhardt \& Noda 1998). We have recently shown that an acidic protein fraction (AF) isolated from mineral acid whey protein concentrate (WPC) had anti-resorptive effects in vitro (Reid et al. 2004). It was therefore of immediate interest to establish whether such fractions had bone bioactivity in vivo. 
In the present study, we investigated whether WAP fractions (AF) isolated from milk could prevent bone loss and bone resorption in mature ovariectomised female rats. We compared three different fractions prepared from mineral acid WPC, lactosereduced mineral acid WPC and lactic acid WPC, respectively. Our primary outcome was in vivo bone mineral density (BMD). Secondary outcomes included bone biomechanics and markers of bone resorption and turnover.

\section{Materials and methods}

Animals

Seventy-five 5.5-month-old female Sprague-Dawley rats were obtained from the Small Animal Production Unit, Massey University, Palmerston North, New Zealand. The animals were shamoperated or ovariectomised (OVX) at age 6 months (week 0 of the study). Sham-operated animals ( $n$ 15) were anaesthetised and an incision was made, but the ovaries were left intact, whereas in the OVX animals the ovaries were removed. These OVX animals were randomised into four groups (fifteen per group).

The animals were housed separately in shoebox cages, and kept in a temperature $\left(22^{\circ} \mathrm{C} \pm 2{ }^{\circ} \mathrm{C}\right)$ and light-controlled $(12 \mathrm{~h}$ daynight cycle) room in the Small Animal Production Unit at Massey University. Animals had access ad libitum to deionised water. Animals were fed a casein-based semi-synthetic diet to which the milk fractions had been added as $3 \mathrm{~kg} / \mathrm{kg}$ (Table 1). The sham control group and the OVX control group received the base diet with no fractions added. The daily intake of the animals was measured, and their intake was adjusted weekly according to the sham group's body weight in order to prevent excessive body weight gain in the OVX groups. The mean food intake over the trial was $20 \mathrm{~g} / \mathrm{d}$ per animal. The trial ran for 4 months, with monthly measurements. Massey University Animal Ethics Committee approved the study $(01 / 70)$

\section{Diets}

The animals were fed a balanced semi-synthetic diet consisting of $15 \%$ caseinate, $5 \%$ cellulose, $5 \%$ corn oil, $0.5 \% \mathrm{Ca}, 62 \%$ starch and added vitamins and minerals as needed from week -2 until week 0 , the week that they were ovariectomised. From week 0 ,

Table 1. Dietary composition $(\mathrm{g} / \mathrm{kg})$

\begin{tabular}{lcc}
\hline & Control & Experimental \\
\hline Sodium caseinate & 150 & 147 \\
Acidic whey protein fraction & & 3 \\
Cystine & $2 \cdot 7$ & $2 \cdot 7$ \\
Glycine & $3 \cdot 3$ & $3 \cdot 3$ \\
Methionine & $1 \cdot 5$ & $1 \cdot 5$ \\
Glutamine & 7 & 7 \\
Cellulose & 50 & 50 \\
Vitamin mix & 50 & 50 \\
Mineral mix* & 50 & 50 \\
Corn oil & 50 & 50 \\
CaCO & & 12.5 \\
Starch & $12 \cdot 5$ & 623 \\
Total & 623 & 1000 \\
\hline
\end{tabular}

*Formulated by Crop \& Food Research, New Zealand, according to the National Research Council (1995) nutrient requirements for laboratory animals (AIN 93M). animals were fed either the control diet (sham and OVX control) or an experimental diet in which the casein content had been adjusted to allow the incorporation of $3 \mathrm{~g} / \mathrm{kg}$ acidic whey protein fraction to the diets. The diet formulation was a modification on AIN-76A. The mineral and vitamin mixes were formulated according to AIN-93M to ensure optimal levels of minerals and trace minerals (National Research Council, 1995) (Table 1).

The dose of the fraction was selected referring to published studies on the milk basic fraction, which ranged between $0.1 \%$ and $1 \%$ of the diet (Takada et al. 1993; Toba et al. 1999, 2000). The following fractions were screened:

mineral acid WPC (AF1);

mineral acid WPC (lactose-reduced) (AF2);

lactic acid WPC (AF3).

\section{Purification of fractions}

Materials. The following whey WPC were obtained from Fonterra Cooperative Group Ltd, Auckland, New Zealand: ALACEN 342 (mineral acid WPC), ALACEN 163 (lactosereduced mineral acid WPC) and ALACEN 312 (lactic acid WPC), Q Sepharose Big Beads were purchased from Amersham Biosciences (Uppsala, Sweden). Dialysis tubing (Spectra/Por, nominal molecular weight cut-off $3 \mathrm{kDa}$ ) was from Spectrum Companies (Ranco Dominguez, CA, USA). Ultrafiltration was carried out using a Prep/Scale spiral-wound membrane cartridge with a nominal molecular weight cut-off of $3 \mathrm{kDa}$ obtained from Millipore (Bedford, MA, USA).

Methods. WAP fractions were prepared from each of the WPC using the same method. Briefly, WPC (2000 g) was reconstituted in 20 litres deionised water and adjusted to $\mathrm{pH} 4.5$ with $10 \% \mathrm{HCl}$. The acidified WPC solution was then loaded on to a 4 litre column packed with Q Sepharose Big Beads. The column was sufficiently washed with deionised water, and the bound protein was eluted with $1 \mathrm{M} \mathrm{NaCl}$. The eluted fraction (6 litres) was then concentrated to $500 \mathrm{ml}$ by ultrafiltration, and the WAP fraction was obtained by freeze-drying, after exhaustive dialysis of the ultrafiltration fraction. The yield of WAP was approximately $100 \mathrm{~g}$.

\section{Tail-vein sampling}

At weeks $-1,4,8,12$ and 16 , rats were placed in a purpose-built restrainer, which was then placed on top of a heat pad and under a heat lamp. A tourniquet was placed around the base of the tail. A single blood sample of approximately $1 \mathrm{ml}$ was withdrawn from the lateral tail vein, using a $23 \mathrm{G} \times 3 / 4$ inch hypodermic needle and $1 \mathrm{ml}$ syringe. Blood samples were transferred immediately into vacutainers containing heparin and then centrifuged at $1000 \mathrm{~g}$ for $10 \mathrm{~min}$. The plasma was removed, snap-frozen with liquid $\mathrm{N}_{2}$ and stored at $-85^{\circ} \mathrm{C}$.

Blood was collected after an overnight fast and between 08.00 and 10.00 hours in the absence of anaesthesia. Plasma collected at weeks $-1,8$ and 16 was used to measure bone biochemical markers, and blood collected at weeks 4 and 12 was used to measure plasma oestrogen levels.

\section{Dual-energy X-ray spectrometry scans}

Animals were scanned for baseline measurements at week -1 , before being ovariectomised at week 0 . Animals were then 
scanned every 4 weeks under anaesthesia up to week 16 after OVX. Animals were weighed and anaesthetised with an appropriate dose of anaesthetic $(0.05 \mathrm{ml} / 100 \mathrm{~g}$ body weight $)$. The anaesthetic was a mixture of $2 \mathrm{ml} / 10 \mathrm{ml}$ acepromazine $+5 \mathrm{ml} / 10 \mathrm{ml}$ ketamine $+1 \mathrm{ml} / 10 \mathrm{ml}$ xylazine $+2 \mathrm{ml} / 10 \mathrm{ml}$ sterile $\mathrm{H}_{2} \mathrm{O}$, and was administered via an intraperitoneal injection using a $25 \mathrm{G} \times 5 / 8$ inch needle and $1 \mathrm{ml}$ syringe. The animals attained a suitable level of anaesthesia approximately 5-10 min after injection and remained under anaesthesia for $2 \mathrm{~h}$.

BMD was measured with a Hologic QDR4000 bone densitometer using a pencil beam unit (Hologic, Bedford, USA). A daily quality control scan was taken to ensure that precision met the required coefficient of variance. The coefficient of variance for the quality control data was $0.98-1 \cdot 01$. Regional high-resolution scans were performed using a 0.06 inch diameter collimator with 0.0127 inch point resolution and 0.0254 inch line-spacing. Rats were placed on an acrylic platform of uniform 1.5 inch thickness. Each rat underwent three regional high-resolution scans of the spine (L1-L4) and left and right femurs. Rats were positioned supine with right angles between the spine and femur, and between the femur and tibia.

Coefficient of variance for the femurs ranged between $0.92 \%$ and $0.85 \%$ with and without repositioning between scans. These values ranged between $1 \%$ and $0.98 \%$ for the spine.

\section{Sampling}

After 16 weeks, animals were weighed and anaesthetised with an appropriate dose of anaesthetic $(0.1 \mathrm{ml} / 100 \mathrm{~g}$ body weight). A $19 \mathrm{G} \times 1.5$ inch needle and $5 \mathrm{ml}$ syringe were used to withdraw blood directly from the heart. Animals were then killed by exposure to $100 \% \mathrm{CO}_{2}$ and dissected.

Blood was placed immediately into heparin-filled tubes and centrifuged at $1000 \mathrm{~g}$ for $10 \mathrm{~min}$; the plasma was then removed, divided into aliquots and snap-frozen. Both the right and left femur and spine were excised with some flesh remaining and frozen in PBS for further analysis. The uteri were removed and weighed to confirm that ovariectomy had been successful.

\section{Bone biomechanics}

The right femurs were scraped clean of adhering flesh and stored in PBS at $-20^{\circ} \mathrm{C}$. Before biomechanical testing, the bones were thawed. The length of the femurs was measured between the proximal end of the intercondylar notch and the proximal limit of the base of the femoral neck using an electronic calliper. The midpoint was marked with a waterproof pen, and the width and thickness at this midpoint were also recorded. The femurs were then incubated at $23^{\circ} \mathrm{C}$ to be at room temperature before and during the test. The femurs were placed in a testing jig constructed for a three-point bending test. The distance between the supporting rods had a fixed length of $12 \mathrm{~mm}$. Load was applied at a constant deformation rate of $50 \mathrm{~mm} / \mathrm{min}$. Maximum load $(\mathrm{N})$, elasticity $\left(\mathrm{N} / \mathrm{mm}^{2}\right)$ and energy $(\mathrm{J})$ were measured using a Shimadzu Ezi-test (Kyoto, Japan).

\section{Bone biochemical markers and plasma oestrogen}

The plasma levels of telopeptides of type I collagen and osteocalcin were measured using the RatLaps and osteocalcin ELISA kits provided by Osteometer BioTech A/S (Herlev, Denmark). Interassay and intra-assay coefficient of variance for both kits were $10 \%$ and $6-7 \%$, respectively. Plasma oestrogen was measured with a double-antibody radioimmunoassay for oestradiol -2 (Diasorin, Stillwater, MN, USA).

\section{Bone ashing}

The left femurs were thawed, scraped clean of remaining flesh and dried overnight at $105^{\circ} \mathrm{C}$. After being weighed, the femurs were ashed overnight at $660^{\circ} \mathrm{C}$ and weighed again.

\section{Statistical analyses}

A total of seventy-five rats (fifteen per group) were used in the trial. Within-group variation is such that a minimum of fourteen animals is needed per group: on calculating the power and sample size (one-way ANOVA) on bone density measurements, a sample size of fourteen is necessary for a power of $0 \cdot 8$. The expected effect was set at $0.02 \mathrm{~g} / \mathrm{cm}^{2}$ for BMD measurements. Results were analysed using Minitab version 13. A $P$ value $<0.05$ was considered to be significant. Groups of animals were compared using repeated measures ANOVA, followed by post hoc testing (Tukey). Values and graphs are expressed and shown as means with their standard error.

\section{Results}

The mean food intake for all the animals was between 18 and $20 \mathrm{~g} / \mathrm{d}$. Table 2 shows the final mean body weights and uterus weights for all groups at week 16 of supplementation (age 10 months). There were no significant differences in the final body weights. The uteri from all the OVX groups were significantly smaller than those of the sham group. Sequential measurement of plasma oestrogen also confirmed that the ovariectomy had been successful (data not shown).

Fig. 1 shows the respective changes in femur and lumbar spine BMD over time. BMD was measured monthly from week -1 to week 16, and the results reflect the changes over time caused by ovariectomy and the effects of feeding the various milk fractions. There was a rapid loss in BMD over the first 4 weeks

Table 2. Final body weights and uterus weights of all groups of rats at week 16 (Mean values and standard errors of the mean)

\begin{tabular}{|c|c|c|c|c|c|c|c|c|c|c|}
\hline & Mean & SEM & Mean & SEM & Mean & SEM & Mean & SEM & Mean & SEM \\
\hline Body weight (g) & 375.5 & $26 \cdot 7$ & $403 \cdot 0$ & $13 \cdot 8$ & $417 \cdot 8$ & $13 \cdot 3$ & 423.9 & 14.5 & $407 \cdot 1$ & $12 \cdot 3$ \\
\hline Uterus weight $(\mathrm{g})$ & 0.98 & 0.11 & 0.28 & $0.08^{*}$ & 0.21 & $0.03^{*}$ & 0.20 & $0.02^{*}$ & 0.25 & $0.06^{*}$ \\
\hline
\end{tabular}

${ }^{*} P<0.05$ v. sham. 

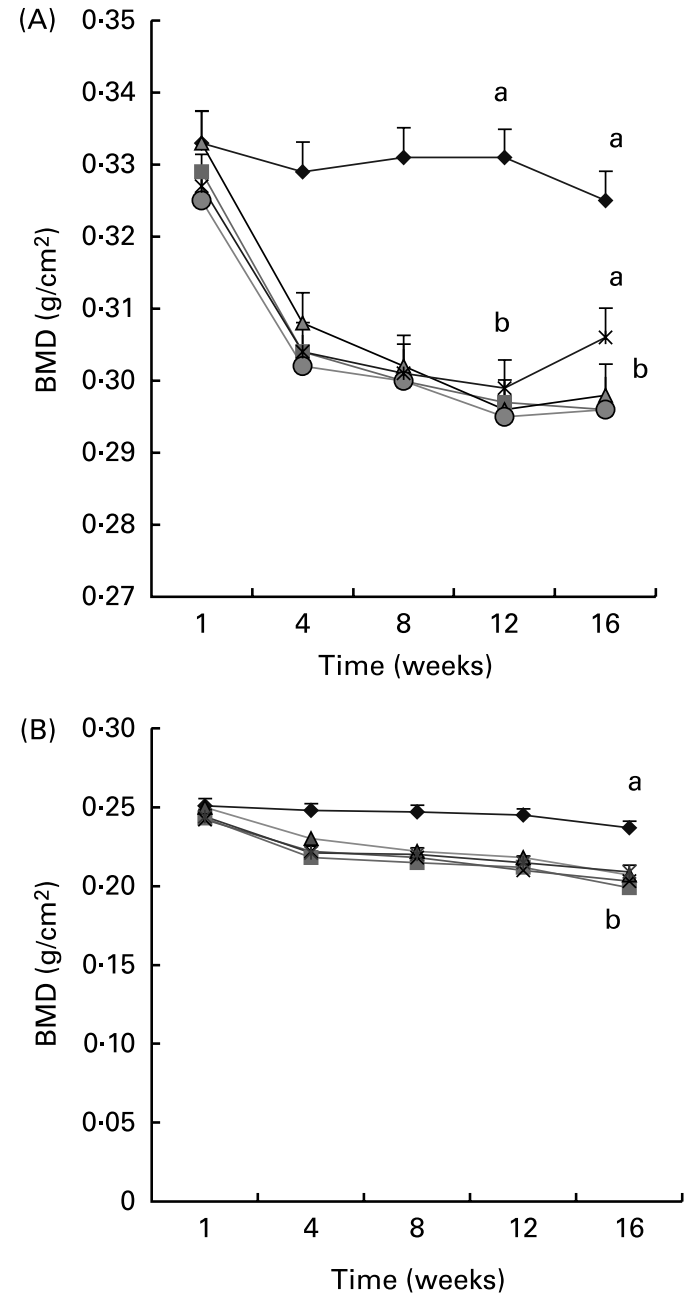

Fig. 1. Sequential bone loss from the femur $(A)$ and lumbar spine $(B)$ shown as bone mineral density (BMD) from week -1 to week 16 for sham operated and ovariectomised rats while being fed acidic whey protein fractions AF1-3

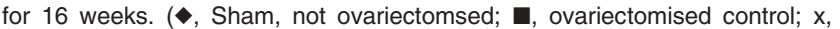
ovariectomised + AF3; $\bullet$ ovariectomised + AF1; $\mathbf{\square}$ ovariectomised + AF2) The whey fraction was added as $3 \mathrm{~g} / \mathrm{kg}$ diet. Values are given as mean and SEM. Note that all OVX groups were different from the sham group at level $P<0.05$ for all weeks measured except for the femurs of the AF3 group at week 16. Different superscripts $(a, b)$ denote significant differences at $P<0.05$.

following ovariectomy for all groups except sham, and this was followed by a more gradual loss over the next 4 weeks. However, the femur BMD for the AF1 and AF3 groups showed an upward trend between weeks 12 and 16, this trend being more prominent for the AF3 group. The lumbar spine did not seem to respond to the same extent as the femur in that all groups except sham lost BMD with no obvious improvement over time.

Fig. 2 shows the in vivo spine bone mineral content (BMC) and bone mineral density (BMD) at 16 weeks. From these data, it appears that all OVX groups lost bone mineral in comparison to the sham control. However, the groups fed AF1 and AF3 had BMC values that were not statistically different from sham animals.

The values for the left and right femurs were averaged for each animal for statistical analysis. Fig. 3 shows the in vivo femur $\mathrm{BMC}$ and BMD, respectively. The femur BMC of the AF1 and AF3 groups was not statistically different from that of the sham control, whereas the other OVX groups lost a significant quantity of
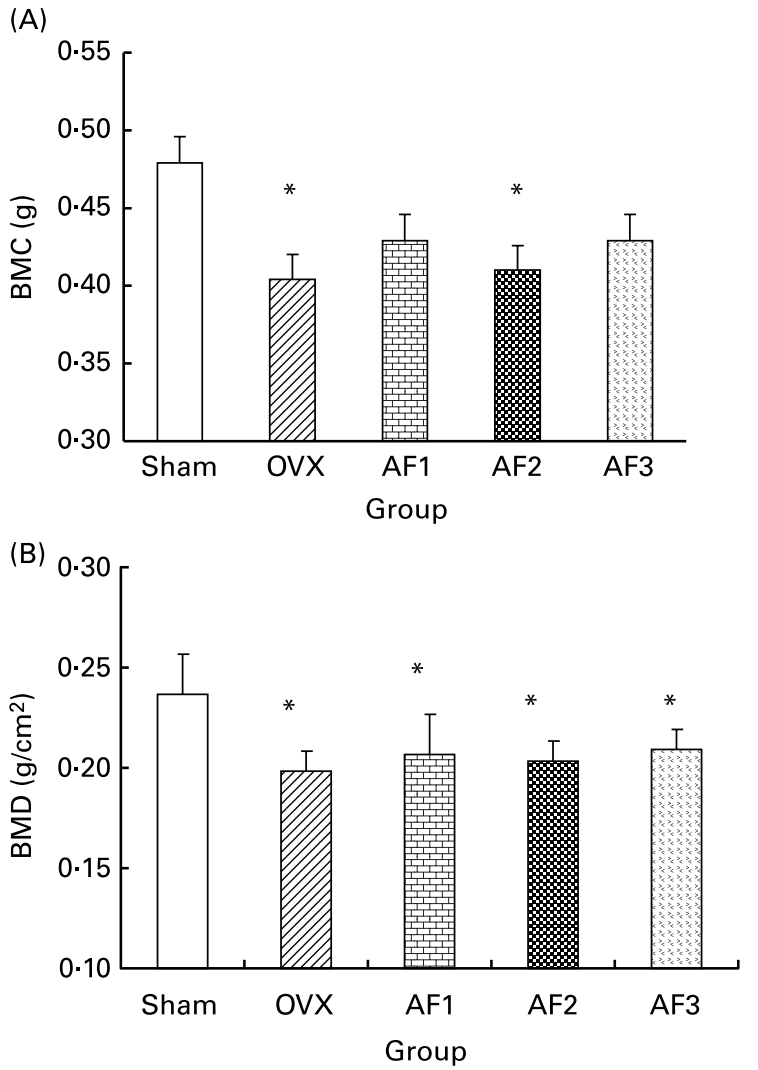

Fig. 2. In vivo (A) spine bone mineral content (BMC) and $(B)$ bone mineral density (BMD) of various groups of rats after being fed acidic whey protein fractions (at $3 \mathrm{~g} / \mathrm{kg}$ diet) for 16 weeks after ovariectomy. The various groups are Sham (ovaries intact), OVX (ovaries removed) and AF1-3 (ovariectomised rats fed acidic whey fractions from milk). Values are means with standard errors shown by veritical bars. *Mean value was significantly different to that of the Sham $(P<0.05)$.

bone compared with the sham control animals $(P<0.05)$. The in vivo femur BMD for all the OVX groups was significantly lower than that of the sham controls, with the exception of the group fed AF3, which had a value not significantly different from that of the sham group and significantly higher than that of OVX controls.

Tables 3 and 4 show the results for the markers of bone resorption (RatLaps; C telopeptide of type I collagen) and bone turnover (osteocalcin), respectively. RatLaps did not change significantly from week -1 to week 8 in all groups. Bone resorption decreased significantly in all the experimental groups as well as in the sham group from week 8 to 16 , but not in the OVX control group.

Osteocalcin, a marker of bone turnover, increased significantly between weeks -1 and 8 in all the OVX groups, whereas it was slightly reduced in the sham group. The increase observed in the OVX groups would be caused by the loss of oestrogen, leading to an increase in bone turnover. At week 16, osteocalcin remained at the same level in the sham group but decreased significantly in all the AF OVX groups. This decrease was more pronounced in the animals fed AF2 and AF3. The percentage change for the various OVX groups between weeks 8 and 16 was $16 \%$ (OVX), $10 \%$ (AF1), 36\% (AF2) and 24\% (AF3). The osteocalcin level for AF3 was significantly higher than that of the sham and OVX controls at week 16 .

Table 5 shows the biomechanical information from the right femurs harvested from the animals at week 16 of supplementation. Femurs harvested from the AF1 group have 
(A)

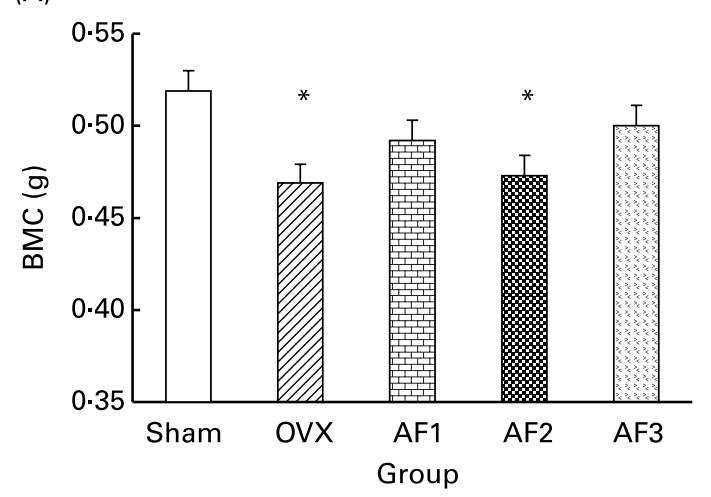

(B)

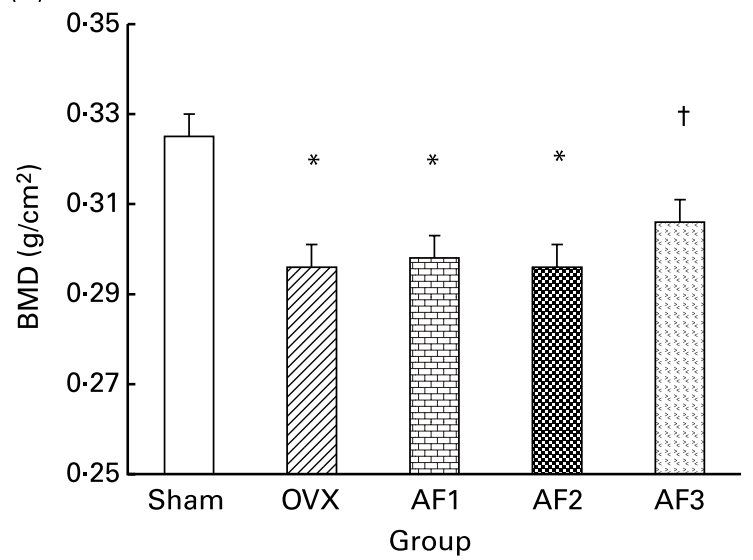

Fig. 3. In vivo (A) femur bone mineral content (BMC) and (B) bone mineral density (BMD) of sham operated and ovariectomised rats after being fed acidic whey protein fractions ( $3 \mathrm{~g} / \mathrm{kg}$ diet) for 16 weeks. The various groups are Sham (ovaries intact), OVX (ovaries removed) and AF1-3 (ovariectomised rats fed acidic whey fractions from milk). Values are means with standard errors shown by vertical bars. Mean values were significantly different to that of the Sham $\left({ }^{\star} P<0.05\right)$ and ovx $\left({ }^{\dagger} P<0.05\right)$. indices that demonstrate that the bones were more stiff than the sham control (break stress and elasticity). Femurs harvested from the AF1 animals were also significantly thicker than the femurs derived from the other groups.

Table 6 summarises further measurements of bone physical properties performed on the left femurs at 16 weeks of dietary intervention. The left femurs harvested from the AF1 group were heavier than those from all other groups. The weights were significantly higher than those of the sham and OVX controls. There was no significant difference in femur ash weight between the five groups. A calculation of organic matter (femur weight - ash weight) showed that the femurs from the supplemented groups had a significantly higher portion of organic matter. This is also reflected in the calculated ratio of ash to organic matter, which was also significantly lower in all the supplemented groups.

\section{Discussion}

In this study, we evaluated three whey AF isolated from bovine milk whey for bone-protective activity. Our model was the aged female OVX rat, and our primary outcome was in vivo BMD. Our results showed that two of the whey AF led to a recovery of some of the bone lost due to ovariectomy. Results also indicated that all three whey AF preserved bone organic matter to a large extent.

There were no significant differences in body weight between the animals at week 16. However, owing to the fact that BMD is influenced by body weight, all statistical analyses on in vivo dual-energy X-ray spectrometry were individually corrected for body weight.

\section{In vivo dual-energy $X$-ray spectrometry}

Femur data show that, between weeks 12 and 16, the BMD started to rise towards that of the sham group for all three supplemented groups, the AF3 group not being significantly different from the sham group at week 16. Although this effect was relatively

Table 3. RatLaps (C telopeptide of type I collagen) values for weeks 0,8 and 16 of rats supplemented with various acidic whey protein fractions from milk Mean values and standard errors of the mean

\begin{tabular}{|c|c|c|c|c|c|c|c|c|c|c|}
\hline \multirow{2}{*}{$\begin{array}{l}\text { RatLaps } \\
\text { Mean (ng/ml) }\end{array}$} & \multicolumn{2}{|c|}{ Sham } & \multicolumn{2}{|c|}{ Ovariectomised } & \multicolumn{2}{|c|}{ AF1 } & \multicolumn{2}{|c|}{ AF2 } & \multicolumn{2}{|c|}{ AF3 } \\
\hline & Mean & SEM & Mean & SEM & Mean & SEM & Mean & SEM & Mean & SEM \\
\hline Week 8 & $8 \cdot 35$ & $1 \cdot 18$ & $9 \cdot 23$ & 1.49 & $12 \cdot 31$ & $1 \cdot 18$ & $13 \cdot 02$ & $1 \cdot 10$ & $12 \cdot 10$ & $1 \cdot 18$ \\
\hline Week 16 & 4.42 & $0.90 \dagger$ & $8 \cdot 79$ & $1 \cdot 14$ & $7 \cdot 20$ & $0.90 \dagger$ & $7 \cdot 75$ & $0.77 \dagger$ & 6.94 & $0.90 \dagger$ \\
\hline
\end{tabular}

$\dagger P<0.05 v$. week 8 within groups.

Table 4. Osteocalcin (marker for bone turnover) values for weeks 0,8 and 16 of rats supplemented with various acidic whey protein fractions (AF) from milk. Mean values and standard errors of the mean

\begin{tabular}{|c|c|c|c|c|c|c|c|c|c|c|}
\hline \multirow{2}{*}{$\begin{array}{l}\text { Osteocalcin } \\
\text { Means (ng/ml) }\end{array}$} & \multicolumn{2}{|c|}{ Sham } & \multicolumn{2}{|c|}{ Ovariectomised } & \multicolumn{2}{|c|}{$\mathrm{AF} 1$} & \multicolumn{2}{|c|}{ AF2 } & \multicolumn{2}{|c|}{ AF3 } \\
\hline & Mean & SEM & Mean & SEM & Mean & SEM & Mean & SEM & Mean & SEM \\
\hline Week 8 & $126 \cdot 4$ & 8.9 & $205 \cdot 6$ & $26 \cdot 6 \ddagger$ & 222.9 & $26 \cdot 3 \ddagger$ & $281 \cdot 2$ & $22 \cdot 0 \ddagger$ & $281 \cdot 8$ & $30.9 \ddagger$ \\
\hline Week 16 & $124 \cdot 3$ & 5.4 & $172 \cdot 3$ & $14 \cdot 9^{*}$ & $201 \cdot 3$ & $13 \cdot 5^{\star}$ & $180 \cdot 1$ & $8 \cdot 3^{*} \dagger$ & $216 \cdot 9$ & $11 \cdot 7^{*} \dagger \S$ \\
\hline
\end{tabular}

Values with different superscripts are significantly different $(P<0.05)$ between groups at the time points as well as within a group over the 16 weeks.

${ }^{\star} P<0.05 \mathrm{~V}$. sham at week 16 .

$\dagger P<0.05 v$. week 8 within groups.

$\ddagger P<0.05 \mathrm{v}$. week -1 within groups, as well as versus sham for all groups at week 8 .

$\S P<0.05 \mathrm{~V}$. ovariectomised at week 16. 






small, the trend was present for all three groups, and it is likely that feeding for a period longer than 16 weeks might have elicited a more pronounced effect. No effect was observed in the spine. Several nutritional trials investigating the effect of nutrients on bone density of the femur and spine have indicated that the effect on bone mineralisation is dependent on the part of the skeleton measured (Scholz-Ahrens et al. 2001).

Additionally, at week 16, the lumbar spine BMC of rats fed AF3 was also not significantly different from sham. The tendency towards an improvement in bone mineralisation following the feeding of AF3 diets was also mirrored in the femoral BMC. In this respect (BMC), it appeared that the AF1 diet was also instrumental in decreasing bone mineral loss resulting from ovariectomy. The bones of the OVX rat continue to grow until the age of 6 months, with significant changes in $\mathrm{Ca}$ and density. From the age of 6 months, changes in femoral density and $\mathrm{Ca}$ are minimal but still present (Kalu, 1991). Increased growth and larger bone size may result in the measurement of an increased $\mathrm{BMC}$ as $\mathrm{BMC}$ is expressed as $\mathrm{Ca}$ per gram bone (Moskilde, 1995). Since the bone lengths and widths of the femurs from the AF1 group were significantly higher than those of the sham and OVX control groups, it is possible that the significantly higher BMC for AF1 was due to a larger bone size.

$\mathrm{Ca}$ absorption was not measured in the present study. However, the whey AF is composed of highly phosphorylated proteins and peptides, some of which are derived from caseins (Sorensen \& Petersen, 1993; Reid et al. 2004). Prevalent among these is proteose peptone 5 , a polypeptide released from $\beta$-casein owing to milk plasmin activity. Phosphorylated peptides from casein have been shown to improve $\mathrm{Ca}$ absorption by binding to the $\mathrm{Ca}$ and maintaining the cation in a soluble form (Camara-Martos \& Amaro-Lopez, 2002). Prior work has also shown that rats fed with casein phosphopeptides had significantly higher femoral and humeral weights than a control group (Tsuchita et al. 1995). It is therefore important to establish whether the presence of phosphorylated casein (and other) peptides in the whey fractions used in this study increased Ca bioavailability, thereby contributing to an observed improvement in bone density.

In respect of composition of the whey AF, it is likely that the fraction from lactose-reduced mineral acid WPC (AF2) contained fewer (phosphorylated) peptides than that derived from mineral acid WPC (AF1). The lactose reduction of mineral acid whey requires repeated ultrafiltration, which would lead to some losses of peptides and small-protein components. On the other hand, in lactic acid whey, the proteins are subjected to proteolysis by lactic acid bacterial enzymes, thus producing more peptide fragments. The tendency for a somewhat greater improvement in bone density indices in the AF3-fed animals may reflect the more proteolysed nature of this fraction. Although caseinoglycomacropeptide, an acidic phosphorylated peptide, has been implicated in the bone health-promoting effects of milk (Neeser et al. 2000), it is most unlikely that that there would have been significant quantities in the fractions studied. Caseinoglycomacropeptide is only prevalent in cheese whey, where it is produced by the specific action of chymosin during the cheesemaking process.

\section{Bone markers}

RatLaps is a marker of bone resorption. It measures the C-telopeptide of type I collagen found in urine or circulating in the blood in greater concentration during bone resorption 
Table 6. Bone parameters for the left femurs for all groups after 16 weeks of feeding various acidic whey protein fractions (AF)

(Mean values and standard erros of the mean)

\begin{tabular}{|c|c|c|c|c|c|c|c|c|c|c|}
\hline \multirow[b]{2}{*}{ Parameter } & \multicolumn{2}{|c|}{ Sham } & \multicolumn{2}{|c|}{ Ovariectomised } & \multicolumn{2}{|c|}{ AF1 } & \multicolumn{2}{|c|}{ AF2 } & \multicolumn{2}{|c|}{ AF3 } \\
\hline & Mean & SEM & Mean & SEM & Mean & SEM & Mean & SEM & Mean & SEM \\
\hline Left femur weight (g) & 0.66 & 0.02 & 0.66 & 0.01 & 0.70 & $0.01 \dagger$ & 0.67 & 0.01 & 0.68 & 0.02 \\
\hline Ashed weight $(\mathrm{g})$ & 0.36 & 0.01 & 0.34 & 0.01 & 0.35 & 0.01 & 0.34 & 0.01 & 0.34 & 0.01 \\
\hline Organic matter $(\mathrm{g}) \ddagger$ & 0.30 & 0.01 & 0.31 & 0.01 & 0.34 & $0.01 \dagger$ & 0.34 & $0.01^{*}$ & 0.34 & $0.01 \dagger$ \\
\hline Ash/organic & $1 \cdot 18$ & 0.03 & $1 \cdot 11$ & 0.03 & 1.01 & $0.03^{*}$ & 1.03 & $0.03^{*}$ & 1.03 & $0.03 \dagger$ \\
\hline
\end{tabular}

${ }^{*} P<0.05$ v. sham.

$\dagger P<0.05 \mathrm{v}$. ovariectomised.

$\ddagger$ Organic matter $=$ left femur weight - ashed weight.

(Swaminathan, 2001; Kruger et al. 2003). The levels of RatLaps between the various groups were not statistically different at baseline. Between weeks -1 and 16 of supplementation, RatLaps decreased in all groups, possibly owing to the feeding of a high-Ca diet, which may to a limited extent be protective against bone resorption. However, the decreases in resorption in the AFsupplemented groups were greater than that of the OVX control group and also statistically significant, thus indicating an antiresorptive effect of the whey AF. An anti-resorptive effect of whey protein as well as an effect on bone formation has been shown before in rat studies using the milk basic protein (Toba et al. 1999, 2000).

Changes in the bone turnover marker osteocalcin are more difficult to interpret as there are no clear-cut trends other than increased bone turnover in the OVX groups as a response to oestrogen deficiency. However, the more dramatic changes in the AF2 and AF3 groups with respect to both the increase and subsequent decrease in serum osteocalcin suggest that these fractions affected bone remodelling in some way.

Whole bovine milk has also been shown to have cell growthpromoting activity in human lymphocytic cells (Klagsbrun \& Neumann, 1979). Several mitogenic factors have been identified in bovine colostrum and milk, such as insulin, IGF-I, IGF-II and transforming growth factor- $\beta$ (Ballard et al. 1982; Cox \& Burk, 1991). In the present study, the WAP exhibited some bone-protective effects and may therefore contain components that promote osteoblast growth. It is unlikely, however, that these effects can be attributed to growth factors such as IGF-I, IGF-II and transforming growth factor- $\beta$ as they were not detectable by ELISA in the whey acidic fractions (results not shown). Growth factors are also generally not absorbed by the adult human intestine (Thomson \& Keelan, 1986; Pacha, 2000). Other potentially bone active proteins include osteopontin and bone sialoprotein (Ito, 1991; Takada et al. 1996).

Osteopontin is a highly phosphorylated and glycosylated protein found in milk and in the extracellular matrix of mineralised tissue (Bayless et al. 1997; Gravallese, 2003). It facilitates the attachment of osteoclasts to the bone matrix via an interaction with cell surface integrins, and it is essential for bone remodelling. Being a highly acidic protein associated with the whey fraction of milk, it is captured in the whey AF from anion exchange (Sorensen \& Petersen, 1993; Reid et al. 2004). Osteopontin in milk would be subject to post-ingestion digestive processes that could release peptides containing the RGD (Arg-Gly-Asp) integrin recognition sequence. RGD peptides and their analogues have been shown to inhibit osteo- clast activity via a competing interaction with integrins (Horton et al. 1991). If RGD peptides released from osteopontin during digestion (or indeed present in the whey either naturally or as a result of processing) are absorbed through the gut, they might well have an effect on osteoclast activity.

\section{Biomechanics}

Bone breaking strength is the maximum power that is required to break bone by the three-point bending method; breaking energy is an integration value of power that is required to make the break. Breaking strength reflects the mineral content of bone as well as the protein component, whereas breaking energy is thought to reflect bone collagen content (Moskilde, 1995; Thompson et al. 1995).

None of the measured parameters in the present study were significantly different, except for the break stress and elasticity (stiffness) of the AF1-fed group. The lack of significant differences except for those two parameters is an indication that, overall, the acidic fractions were not detrimental to bone. Differences in breaking strength are linearly related to femur Ca content (Moskilde, 1995; Thompson et al. 1995). However, correcting the biomechanical data for bone $\mathrm{Ca}$ content in the present study did not change the final outcomes or conclusions. Previous work indicated that feeding whey basic protein increased the amount of bone protein such as collagen in rats, thereby enhancing bone breaking force (Takada et al. 1997a,b). Some effect on breaking force due to feeding AF3 was observed in this study; the result was, however, not statistically significant.

Further investigation into bone weight, and the ratio between ash content of the bones and the organic matter, indicated that AF1 increased bone weight towards sham-treated levels. A calculation of the organic matter in the bones showed that the $\mathrm{AF}$ groups all had a significantly higher quantity of organic matter compared with the sham group, whereas that of the AF1 group was significantly higher than the value for the OVX group as well.

Recalcification of bone takes place with bone collagen as a scaffold (Termine \& Robey, 1996). It is possible that in the groups fed WAP, bone loss was slowed by first building the organic phase of the bone, with calcification following later. The AF diets had an anti-resorptive effect resulting in lower levels of type I collagen fragments in the circulation at the termination of the study. Bone resorption occurs in two phases, being initiated by matrix metalloproteinases, which release the cross-linked carboxy-terminal telopeptide of type I collagen into the circulation. This initial phase is then followed by further destruction by cathepsin $\mathrm{K}$, a cysteine proteinase that releases the car- 
boxy-terminal cross-linked peptide of type I collagen into the circulation. The latter is measured by the RatLaps assay. From the results of the present study, it is therefore possible that the whey protein acidic fraction might also have exerted an effect through the cysteine proteinases (Parikka et al. 2001). Although milk does contain cystatin C, a naturally ocurring cathepsin K inhibitor (Lerner et al.1997; Toba et al. 2000), it is unlikely to be associated with the whey AF from milk (Toba et al. 2000).

\section{Conclusion}

The results of this study suggest that the AF from both mineral acid whey and lactic acid whey may lead to a remediation of the bone loss associated with ovariectomy. Femoral bone density was significantly increased in the animals fed the lactic whey acidic fraction after 4 months of feeding. Biomechanical data showed that the AF may affect bone collagen. Further measurements and calculation confirmed that the organic phase of the bones was affected. The whey AF may contain components that may act on bone, such as osteopontin or cysteine proteinase inhibitors.

The present study was undertaken in a high-Ca $(0.5 \%)$ environment compared with previous studies, in which a Ca level of $0 \cdot 1-$ $0.3 \%$ was used (Toba et al. 1999, 2000). It is therefore possible that the high Ca level has masked some of the effects of the whey proteins. Further work is being undertaken to identify any bone-active factors that may be present in the whey protein acidic fraction.

From a human dietary perspective, the mean food intake of the rats, at $50 \mathrm{~g} / \mathrm{kg}$ per $\mathrm{d}$ (calculated from the mean weight of the rats and the average daily intake), equates to an intake of $0 \cdot 15 \mathrm{~g}$ acid protein fraction $/ \mathrm{kg}$ per $\mathrm{d}$. In human terms, this would equate to an intake of $9 \mathrm{~g}$ acid protein fraction/d for an average female weighing $60 \mathrm{~kg}$. The AF from whey constitutes approximately $3 \%$ of the total milk protein and occurs at a level of about $1 \mathrm{~g} / \mathrm{l}$ (Tremblay et al. 2003). Thus, the above intake of WAP would be the equivalent of 9 litres of milk. However, with respect to protein, the WAP constituted $2 \%$ of the protein in the rat diet. Given the daily recommended protein intake of $1.7 \mathrm{~g} / \mathrm{kg}$ per $\mathrm{d}$ for adult human females, a similar percentage would give an intake requirement of $2.04 \mathrm{~g}$ $\mathrm{WAP} / \mathrm{day}$, or the equivalent of 2 litres of milk. In terms of dietary bone prophylaxis, the incorporation of small amounts of WAP into the diet would therefore present a more attractive option than the consumption of large volumes of milk.

\section{Acknowledgements}

The authors would like to thank Kath Brown, Lily Feng and Nicky Frearson for excellent technical assistance, and Fonterra Cooperative Group Ltd for funding the study.

\section{References}

Ballard FJ, Nield MK, Francis GL, Dahlenberg GW \& Wallace JC (1982) The relationship between the insulin content and inhibitory effect of bovine colostrums on protein breakdown in cultured cells. $J$ Cell Physiol 110, 249-254.

Bayless KJ, David GE \& Meininger GA (1997) Isolation and biological properties of osteopontin from bovine milk. Prot Expression Purif $\mathbf{9}$, 309-314.
Camara-Martos F \& Amaro-Lopez MA (2002) Influence of dietary factors on calcium bioavailability. Biologic Trace Element Res 89, 43-52.

Cox DA \& Burk R (1991) Isolation and characterisation of milk growth factor, a transforming-growth-factor-beta 2-related polypeptide from bovine milk. Eur J Biochem 197, 353-358.

Delisle J, Amiot J \& Dore F (1995) Biological availability of calcium and magnesium from dairy products. Int Dairy $J$ 5, 87-96.

Denhardt DT \& Noda M (1998) Osteopontin expression and function: role in bone remodelling. J Cell Biochem 30/31, Suppl., 92-102.

Gravallese EM (2003) Osteopontin: a bridge between bone and the immune system. J Clin Invest 112, 147-148.

Heaney RP (2000) Calcium, dairy products and osteoporosis. J Am Coll Nutr 19, 83S-99S.

Horton MA, Taylor ML, Arnett TR \& Helfrich MH (1991) Arg-Gly-Asp (RGD) peptides and the anti-vitronectin receptor antibody $23 \mathrm{C} 6$ inhibit dentine resorption and cell spreading by osteoclasts. Exp Cell Res $\mathbf{1 9 5}$, $368-375$.

Ito T (1991) Science of breast milk. New Food Ind 33, 73-80.

Kalu DN (1991) The ovariectomised rat model of postmenopausal bone loss. Bone Mineral 15, 175-192.

Kelly O, Cusack S \& Cashman KD (2003) The effect of bovine whey protein on ectopic bone formation in young growing rats. Brit J Nutr $\mathbf{9 0}$, $557-564$.

Klagsbrun M \& Neumann J (1979) The mitogenic effect of human breast milk. J Surg Res 26, 417-422.

Kruger MC, Brown KE, Collett GG, Layton L \& Schollum LM (2003) The effect of fructooligosaccharides with various degrees of polymerisation on calcium bioavailability in the growing rat. Exp Biol Med 228, $683-688$.

Lerner UH, Johansson L, Ranjso M, et al. (1997) Cystatin C, an inhibitor of bone resorption produced by osteoblasts. Acta Physiol Scand 161, 81-92.

Moskilde L (1995) Assessing bone quality - animal models in preclinical osteoporosis research. Bone 17, 343S-352S.

National Research Council (1995) Nutrient Requirements of Laboratory Animals, 4th edn. Washington DC, USA: National Academic Press.

Neeser J-R, Offord CE, Felix R, et al. (2000) Milk protein hydrolysate for addressing bone as a dental disorder. World patent WO 00/49885.

Omi N \& Ezawa I (1995) The effect of ovariectomy on bone metabolism in rats. Bone 17, $163 \mathrm{~S}-168 \mathrm{~S}$.

Pacha J (2000) Development of intestinal transport function in mammals. Physiol Rev 80, 1633-1667.

Parikka V, Lehenkari P, Sassi M-J, et al. (2001) Estrogen reduces the depth of resorption pits by disturbing the organic matrix degradation activity of osteoclasts. Endocrinol 142, 5371-5378.

Price JS, Oyajobi BO \& Russell RG (1994) The cell biology of bone growth. Eur J Clin Nutr 48, 131-149.

Reid IR, Cornish J, Haggarty NW, Palmano KP (2004) Bone health compositions derived from milk. US patent US2004052860.

Scholz-Ahrens KE, Schaafsma G, Van der Heuvel EGHM \& Schrezenmeir J (2001) Effects of prebiotics on mineral metabolism. Am J Clin Nutr 73, Suppl., 459S-464S.

Sorensen ES \& Petersen T (1993) Purification and characterization of three proteins from the proteose peptone fraction of bovine milk. J Dairy Res 60, 189-197.

Swaminathan R (2001) Biochemical markers of bone turnover. Clin Chim Acta 313, 95-105.

Takada Y, Aoe S \& Kumegawa M (1996) Whey protein stimulates cell proliferation and differentiation of osteoblastic MC3T3-E1 cells. Biochem Biophys Res Commun 223, 445-449.

Takada Y, Kobayashi N, Kato K, et al. (1997a) Effects of protein on calcium and bone metabolism in ovariectomised rats. J Nutr Sci Vitaminol 43, 199-210.

Takada Y, Matsuyama H, Kato K, et al. (1997b) Milk whey protein enhances the bone breaking force in ovariectomised rats. Nutr Res 17, 1709-1720.

Takada Y, Yahiro M \& Nakajima I (1993) Effect of milk components on calcium absorption and bone metabolism. In Characterisation of Milk 
Components and Health, pp. 171-185 [K Yamauchi, T Imamura and T Morita, editors]. Tokyo: Kousikan.

Termine JD \& Robey PG (1996) Bone matrix and the mineralisation process. In Primer on the Metabolic Bone Diseases and Disorders of Mineral Metabolism, 3rd ed., pp. 24-28 [MJ Favus, editor]. New York: Lippincott-Raven, American Society of Bone and Mineral Research.

Thomson AB \& Keelan M (1986) The development of the small intestine. Can J Phys Pharmacol 64, 13-29.

Thompson DD, Simmons HA, Pirie CM \& Ke HZ (1995) FDA Guidelines and animal models for osteoporosis. Bone 17, 125S133 S.
Toba YT, Takada Y, Tanaka M \& Aoe S (1999) Comparison of the effects of milk components and calcium source on calcium bioavailability in growing male rats. Nutr Res 19, 449-459.

Toba Y, Takada Y, Yamamura J, et al. (2000) Milk basic protein: a novel protective function of milk against osteoporosis. Bone 27, 403-408.

Tremblay L, Laporte MF, Leonil J, Dupont D \& Paquin P (2003) Quantitation of proteins in milk and milk products. In Advanced Dairy Chemistry, 3rd ed., vol. 1 Proteins, p. 55-65 [PF Fox and PLH McSweeney, editors]. New York: Kluwer-Plenum.

Tsuchita H, Goto T \& Yonehara Y (1995) Calcium and phosphorus availability from casein phosphopeptides in male growing rats. Nutr Res $\mathbf{1 5}$, $1657-1667$. 